\section{Evaluation of Nine Positive Pressure Suits for Use in the Biosafety Level-4 Laboratory}

\author{
Samantha Beth Kasloff', Peter Marszal', and Hana M. Weingartl ${ }^{1,2}$
}

Applied Biosafety:

Journal of ABSA International

2018, Vol. 23(4) 223-232

(C) ABSA International 2018

Article reuse guidelines:

sagepub.com/journals-permissions

DOI: $|0.1177 /| 53567601879315 \mid$

journals.sagepub.com/home/apb

(QSAGE

\begin{abstract}
Positive pressure suits are the most recognizable feature of Biosafety Level 4 (BSL-4) laboratories, protecting users both through delivery of umbilical-fed HEPA-filtered air and by providing a positively pressurized microenvironment with respect to the surrounding laboratory space to minimize the possibility of exposure resulting from compromised suit integrity. While many positive pressure suits utilized in the chemical and radiation protection industries could be considered for BSL-4 use, the substantial costs and potential incompatibilities with facility settings prevent many labs from investigating novel alternatives. In the present study, 9 positive pressure suits from 5 different manufacturers were critically assessed for their suitability in the BSL-4 laboratory. Material resistance and compatibility with $5 \%$ Micro-Chem Plus ${ }^{\mathrm{TM}}, \mathrm{CO}_{2}$ exposure levels, and overall user preference were assessed through a combination of objective and subjective testing. Results demonstrated that exposure to $5 \%$ Micro-Chem Plus $^{\mathrm{TM}}$ had no deleterious effects on the mechanical properties of most suit materials, though some potential incompatibility was observed with butyl fabrics. Real-time monitoring of $\mathrm{CO}_{2}$ levels inside the suits showed a great deal of variation between models, however all suits provided a microenvironment where users were exposed to $\mathrm{CO}_{2}$ levels below $1 \%$ during normal activity and less than $2 \%$ during periods of disconnect from supply air. Finally, survey results from study participants indicated a strong preference for suits with light construction material, 360-degree visibility, high delivery airflow and gloves that require fixation by taping. By combining the present results with facility-specific factors, laboratories will be better equipped to consider new models that best suit their needs.
\end{abstract}

\title{
Keywords
}

positive pressure suits, biosafety level 4, personnel protective equipment, laboratory biosafety, $\mathrm{CO}_{2}$ exposure

Biosafety Level 4 (BSL-4) laboratories are highly complex containment facilities where a combination of engineering, safety equipment and operational practices allows for the safe handling of risk group level 4 pathogens. Such laboratories are found in 1 of 2 configurations; cabinet lines, consisting of a series of Class III biological safety cabinets, and suit labs, where laboratorians don positive pressure suits to enter and work in the laboratory. In spite of the higher associated running costs and high degree of precision required while working, suit laboratories provide a number of practical advantages over Class III cabinet laboratories due to reduced space constraints for housing equipment and the ability to work with larger animal models.

Positive pressure suits are self-encapsulating garments with an umbilical-fed external air supply that protect the user in 2 ways: the suit itself creates a complete physical barrier between the laboratorian and the surrounding laboratory space, while the positive pressure within the suit minimizes the risk of exposure to contaminated air in the event of a material breach. While these suits have become synonymous with maximum containment infectious disease work, they were originally developed by the US Army for use at chemical weapons sites. ${ }^{1}$ Consultation with international biosafety reference materials reveals that there are in fact very few criteria that define what type of suit can be worn in BSL-4. Neither the WHO Laboratory Biosafety Manual nor the US Department of Health and Human Services' Biosafety in Microbiological and Biomedical Laboratories specifically define a positive pressure suit, and instead make reference to a "full-body, one-piece positive pressure HEPA air supplied suit.",2,3 The Canadian Biosafety Handbook slightly expands on this description with a dedicated section to describe positive pressure suits and makes mention of head-to-toe coverage that includes integral boots, gloves, and headpiece as well as integrity testing to ensure that suits

\footnotetext{
${ }^{\prime}$ Canadian Food Inspection Agency, Winnipeg, Manitoba, Canada

${ }^{2}$ University of Manitoba, Winnipeg, Manitoba, Canada

Corresponding Authors:

Samantha Beth Kasloff, Special Pathogens Unit, National Center for Foreign Animal Disease, Canadian Food Inspection Agency, 1015 Arlington Street, Winnipeg, Manitoba R3E 3M4, Canada.

Email: Samantha.kasloff@canada.ca

Hana M. Weingartl, Special Pathogens Unit, National Center for Foreign Animal Disease, Canadian Food Inspection Agency, 1015 Arlington Street, Winnipeg, Manitoba R3E 3M4, Canada.

Email: hana.weingartl@canada.ca
} 
are gas tight without tears or leaks and able to maintain a fixed positive pressure when inflated. ${ }^{4}$ Despite these loose definitions, the market for BSL-4 suits has been dominated by 3 manufacturers for the past several decades.

While the use of positive pressure suits provides a great deal of flexibility in terms of scale and scope of experimental work compared to cabinet labs, the ergonomics, noise levels, and microenvironment inside the suit present a challenge to users while performing even routine tasks. In addition, the suit materials must be compatible with the disinfectant used for the chemical decontamination shower, which may vary between countries and facilities due to environmental regulations, shower delivery systems, and costs. Due to the limited number of facilities with BSL-4 capability, publications detailing the selection and evaluation of BSL-4 suits are extremely limited. In 2011 Kümin et al published the only manuscript to date containing objective and subjective experimental comparisons of the 3 widely used positive pressure suit models, ${ }^{5}$ providing the ground work upon which the present work was designed. The following year, a publication by Steward and Lever characterized operator protection factors of intact and damaged suits using a make and model not included in the previous study; however the use of an animated mannequin did not allow for consideration of user comfort. ${ }^{6}$

With enhanced public scrutiny over recently publicized incidents involving high containment BSL-4 laboratories, there is a heightened sense of urgency to assure the public that these facilities operate in accordance with the highest levels of biosafety and biosecurity. Further, as new BSL-4 facilities are opening or in the planning phases, a clear need has been addressed to aid in the selection of program-specific positive pressure suits that are protective, user-friendly, and compatible with facility parameters, including backup air capacity and choice of disinfectant. The present study is the first of its kind to perform a comprehensive large-scale evaluation of 9 positive pressure suits for use in the BSL-4 laboratory, including widely used models as well as others that have never-before been used in a BSL-4 setting. Through evaluation of user feedback, assessment of suit material compatibility with 5\% MicroChem Plus ${ }^{\mathrm{TM}}$, and analyses of $\mathrm{CO}_{2}$ accumulation in the suit microenvironment, we have identified a combination of factors and features of positive pressure suits required for safe and user-friendly operation in the BSL-4 laboratory setting.

\section{Materials and Methods}

\section{Positive Pressure Suits}

Nine positive pressure suits from 5 different manufacturers (Table 1, Figure 1) were evaluated in the course of this study. For participant-driven analyses, supplied airflow was adjusted for each suit based on manufacturer's requirements. Ambient temperature, HEPA-filtered air was delivered to each suit at $20 \%$ above the low end of the recommended range $( \pm 5 \%)$ using a 1-1000 L/min-range Mass Flow Meter (Model FMA1845A, Omega Engineering) with an added 1-100 PSI pressure gauge (SwagelokO) to monitor throughout the process. Specific flow rates used were as follows: suits 1-4: 376 $\mathrm{L} / \mathrm{min}$; suit 5: $550 \mathrm{~L} / \mathrm{min}$; suit 6: $160 \mathrm{~L} / \mathrm{min}$; suits 7-8: 260 L/min; suit 9: $202 \mathrm{~L} / \mathrm{min}$.

\section{Mechanical Properties of Suit Materials}

Swatches of 9 suit materials received either directly from the manufacturer or taken from new suits in house were assessed for their resistance to the disinfectant used in the BSL-4 chemical shower. Micro-Chem Plus ${ }^{\mathrm{TM}}$ (National Chemical Laboratories, Inc, Philadelphia, PA, USA) was prepared at a working concentration of $5 \% \mathrm{v} / \mathrm{v}$ in water as per institutional protocol. Swatches were completely submerged in the Micro-Chem Plus $^{\mathrm{TM}}$ solution for a total of 5 days, rinsed with water, blotted dry and then air-dried overnight at room temperature. Given our institutional chemical shower parameters of a 2-minute chemical wash followed by 3 minute water rinse, the 5-day exposure period corresponded roughly to 2 chemical showers per day over a period of 5 years. To determine the effect of the disinfectant on BSL-4 suit integrity, materials were assessed for their resistance to puncture, abrasion, and flex-cracking. An equal number of untreated control samples were included for comparison, and all materials were tested for performance requirements of Type $1 \mathrm{C}$ gas-tight chemical protective suits as defined in the Canadian Standard CAN/CGSB/CSAZ16602:14 Protective clothing for protection against chemicals-Classification, labeling and performance requirements (ISO 16602:2007+A1:2012, MOD). ${ }^{7}$

$2 A$. Resistance to puncture was measured in accordance with ISO 13996:1999 "Protective clothing-Mechanical properties-Determination of resistance to puncture" using 4 test specimens sized $63 \times 63 \mathrm{~mm}$ at a testing speed of $100 \mathrm{~mm} / \mathrm{min}$.

2B. Resistance to flex-cracking was measured in accordance with ISO 7854:1995, Method B Rubber- or plastic-coated fabrics-Determination of resistance to damage by flexing. Four test specimens measuring $105 \mathrm{~mm}$ long $\times 50 \mathrm{~mm}$ wide were prepared from crosswise ( 2 specimens) and lengthwise ( 2 specimens) sections of each material. Samples were subjected to 40000 test cycles with a flexing frequency of $8.3 \pm 0.4 \mathrm{~Hz}$ and stroke length of $11.7 \pm 0.35 \mathrm{~mm}$. Observed material damage to each swatch was recorded and assigned a numerical damage score (indicated in square brackets) for graphical purposes: unchanged [0], lightly creased [1], creased [2], creased with pin holes [3], or creased with small hole [4].

$2 C$. Resistance to abrasion was measured in accordance with EN 530:2010 "Abrasion resistance of protective clothing materials - Test methods. Method 2" using 4 circular test specimens with a $140 \mathrm{~mm}$ diameter. Testing was performed with a silicon carbide, P150 paper abradant (grain size $<90 \mu \mathrm{m}$ ), $9 \mathrm{kPa}$ of applied pressure, and measured up to 2000 cycles. As a complement to the above test, the change in mass $\left(\mathrm{g} / \mathrm{m}^{2}\right)$ of 1 specimen of each material per treatment group was calculated after 2000 abrasion cycles. 
Table I. Structural Characteristics of 9 Positive Pressure Suits Included for Comparison.

\begin{tabular}{|c|c|c|c|c|c|c|c|c|c|}
\hline Suit & $\begin{array}{l}\text { Airflow } \\
\text { Required }\end{array}$ & Body & Zipper & $\begin{array}{l}\text { Glove } \\
\text { System }\end{array}$ & Seams & Visor & $\begin{array}{l}\text { Exhaust } \\
\text { Valves }\end{array}$ & $\begin{array}{l}\text { Internal Air } \\
\text { Distribution }\end{array}$ & $\begin{array}{l}\text { Additional } \\
\text { Features }\end{array}$ \\
\hline I & $360-440 \mathrm{~L} / \mathrm{min}$ & $\begin{array}{l}\text { Double-faced } \\
\text { polyester fabric } \\
\text { coated with } \\
\text { Viton }{ }^{\circledR} \text { coating } \\
\text { \& butyl } \\
\text { undercoat }\end{array}$ & $\begin{array}{l}\text { Downward } \\
\text { closing, fitted } \\
\text { vertically on } \\
\text { right hand side }\end{array}$ & $\begin{array}{l}\text { Locking cuff- } \\
\text { dry glove } \\
\text { system }\end{array}$ & $\begin{array}{l}\text { Stitched and } \\
\text { double taped }\end{array}$ & $180^{\circ}$ & $\begin{array}{l}\text { Back of } \\
\text { hood (2) } \\
+ \text { back (3) }\end{array}$ & $\begin{array}{l}\text { Hose delivery to } \\
\text { arms and legs, } \\
2 \text { hoses on } \\
\text { connecting } \\
\text { collar in hood } \\
\text { area }\end{array}$ & $\begin{array}{l}\text { Internal } \\
\text { support belt, } \\
\text { low airflow } \\
\text { alarm }\end{array}$ \\
\hline 2 & $360-440 \mathrm{~L} / \mathrm{min}$ & $\begin{array}{l}\text { Double-faced, } \\
\text { bromobutyl- } \\
\text { coated } \\
\text { polyester fabric }\end{array}$ & $\begin{array}{l}\text { Downward } \\
\text { closing, fitted } \\
\text { vertically on } \\
\text { right hand side }\end{array}$ & $\begin{array}{l}\text { Locking cuff } \\
\text { dry glove } \\
\text { system }\end{array}$ & $\begin{array}{l}\text { Stitched and } \\
\text { double taped }\end{array}$ & $180^{\circ}$ & $\begin{array}{l}\text { Back of } \\
\text { hood (2) }+ \\
\text { back (3) }\end{array}$ & $\begin{array}{l}\text { Hose delivery to } \\
\text { arms and legs, } \\
2 \text { hoses on } \\
\text { connecting } \\
\text { collar in hood } \\
\text { area }\end{array}$ & $\begin{array}{l}\text { Internal } \\
\text { support belt, } \\
\text { low airflow } \\
\text { alarm }\end{array}$ \\
\hline 4 & $360-440 \mathrm{~L} / \mathrm{min}$ & $\begin{array}{l}\text { Double-faced, } \\
\text { neoprene- } \\
\text { coated } \\
\text { polyester fabric }\end{array}$ & $\begin{array}{l}\text { Downward } \\
\text { closing, fitted } \\
\text { vertically on } \\
\text { right hand side }\end{array}$ & $\begin{array}{l}\text { Locking cuff } \\
\text { dry glove } \\
\text { system }\end{array}$ & $\begin{array}{l}\text { Stitched and } \\
\text { double taped }\end{array}$ & $180^{\circ}$ & $\begin{array}{l}\text { Back of } \\
\text { hood (2) }+ \\
\text { back (3) }\end{array}$ & $\begin{array}{l}\text { Hose delivery to } \\
\text { arms and legs, } 2 \\
\text { hoses on } \\
\text { connecting } \\
\text { collar in hood } \\
\text { area }\end{array}$ & $\begin{array}{l}\text { Internal } \\
\text { support belt, } \\
\text { low airflow } \\
\text { alarm }\end{array}$ \\
\hline 5 & $450-950 \mathrm{~L} / \mathrm{min}$ & $\begin{array}{l}\text { Reinforced } \\
\text { PVC-coated } \\
\text { fabric }\end{array}$ & $\begin{array}{l}\text { Downward- } \\
\text { closing with } \\
\text { exposed teeth }\end{array}$ & Tape & Welded, flat & $360^{\circ}$ & $\begin{array}{l}\text { Hood (I) } \\
+ \text { Upper } \\
\text { back (I) }\end{array}$ & $\begin{array}{l}\text { Hose delivery to } \\
\text { arms and legs, } \\
\text { I diffuser at } \\
\text { bottom of visor }\end{array}$ & \\
\hline 7 & $220-475 \mathrm{~L} / \mathrm{min}$ & $\begin{array}{l}\text { Polyamide fabric } \\
\text { coated with } \\
\text { PVC on both } \\
\text { sides }\end{array}$ & $\begin{array}{l}\text { Downward } \\
\text { closing, } \\
\text { chloroprene } \\
\text { rubber coated } \\
\text { zipper with } \\
\text { splash guard }\end{array}$ & $\begin{array}{l}\text { Bayonet } \\
\text { glove ring } \\
\text { system }\end{array}$ & $\begin{array}{l}\text { Stitched and } \\
\text { sealed with } \\
\text { welded-on } \\
\text { tape on } \\
\text { outside }\end{array}$ & $180^{\circ}$ & $\begin{array}{l}\text { Back of } \\
\text { hood (4) }\end{array}$ & $\begin{array}{l}\text { Two air } \\
\text { diffusers in } \\
\text { hood area }\end{array}$ & $\begin{array}{l}\text { Internal } \\
\text { support belt, } \\
\text { low airflow } \\
\text { alarm }\end{array}$ \\
\hline 8 & $220-475 \mathrm{~L} / \mathrm{min}$ & $\begin{array}{l}\text { Polyamide fabric } \\
\text { with inner } \\
\text { chloroprene } \\
\text { rubber coating } \\
\text { and outer } \\
V^{\circledR} \text { iton }{ }^{\circledR} \text { coating } \\
\text { \& butyl } \\
\text { undercoat }\end{array}$ & $\begin{array}{l}\text { Downward } \\
\text { closing, } \\
\text { chloroprene } \\
\text { rubber coated } \\
\text { zipper with } \\
\text { splash guard }\end{array}$ & $\begin{array}{l}\text { Bayonet } \\
\text { glove ring } \\
\text { system }\end{array}$ & $\begin{array}{l}\text { Double } \\
\text { stitched } \\
\text { covered with } \\
\text { outer Viton } \\
\text { rubber tape } \\
\text { and inner } \\
\text { fabric- } \\
\text { reinforced } \\
\text { tape }\end{array}$ & $180^{\circ}$ & $\begin{array}{l}\text { Back of } \\
\text { hood (4) }\end{array}$ & $\begin{array}{l}\text { Two air } \\
\text { diffusers in } \\
\text { hood area }\end{array}$ & $\begin{array}{l}\text { Internal } \\
\text { support belt, } \\
\text { low airflow } \\
\text { alarm }\end{array}$ \\
\hline 9 & $78-702 \mathrm{~L} / \mathrm{min}$ & $\begin{array}{l}\text { Double-faced, } \\
\text { PVC-coated } \\
\text { fabric }\end{array}$ & $\begin{array}{l}\text { Downward } \\
\text { closing, fitted } \\
\text { vertically on } \\
\text { right-hand side }\end{array}$ & Tape & Welded, flat & $>300^{\circ}$ & $\begin{array}{l}\text { Back of } \\
\text { hood (4) }\end{array}$ & $\begin{array}{l}\text { Hose delivery to } \\
\text { arms and legs, } \\
\text { diffuser at } \\
\text { bottom of visor }\end{array}$ & \\
\hline
\end{tabular}




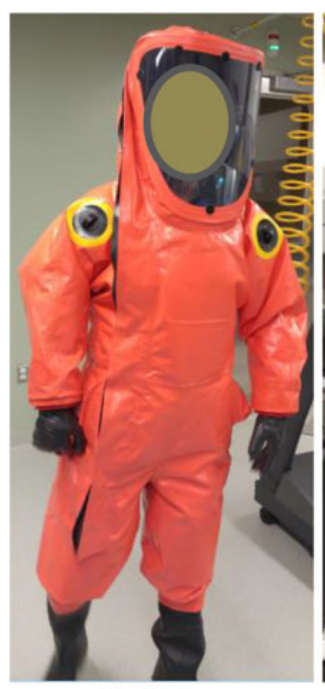

Suit 1

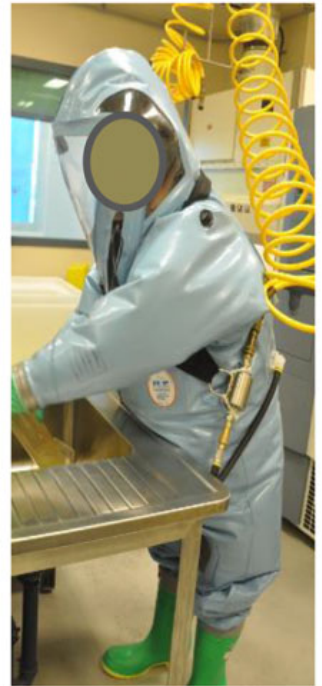

Suit 6

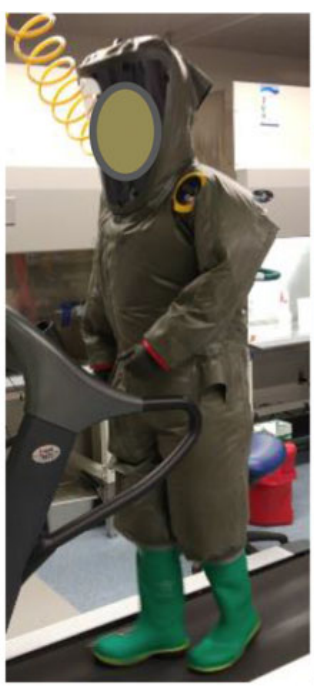

Suit 2

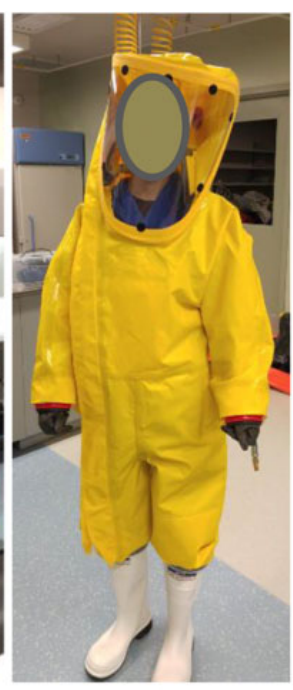

Suit 3

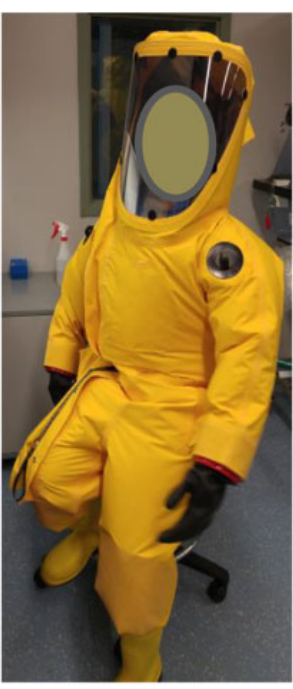

Suit 4

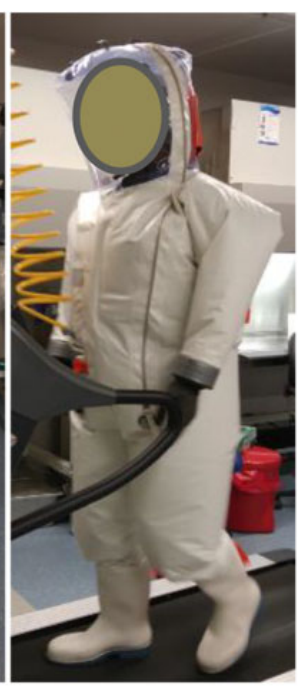

Suit 5

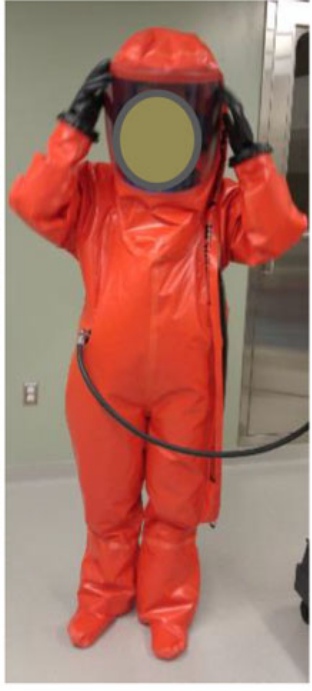

Suit 7

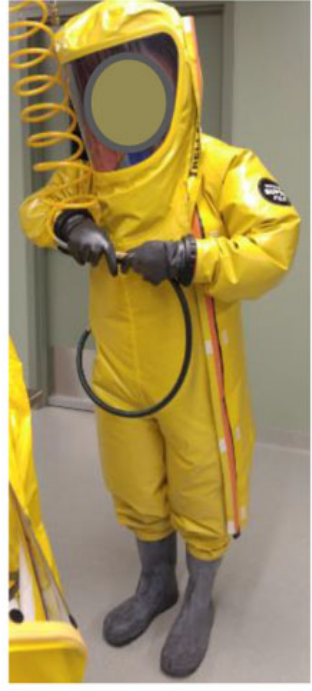

Suit 8

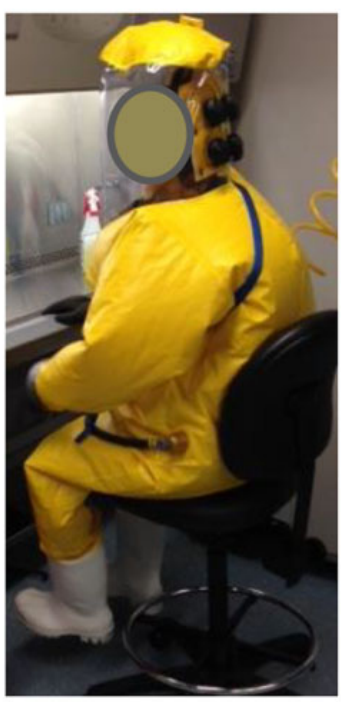

Suit 9

Figure I. Positive pressure suit models from 5 different manufacturers utilized in the study.

\section{User Preference for Positive Pressure Suits}

A total of 15 staff members participated in the suit study, with the majority testing 2 suits each. Participants (5 per suit) were requested to change into scrubs and don the suit. Once connected to air, individuals performed a series of actions simulating typical work in the BSL-4 laboratory: walking, disconnecting and reconnecting to air drops, carrying items to and from the biosafety cabinet, sitting at the BSC and pipetting, and bending to reach objects on the floor from a sitting and standing position ( $\mathrm{n}=5$ per suit). Following these activities and a 5 minute walk on a treadmill (described below), individuals doffed the suits and were asked to complete an anonymous survey describing their overall impressions. Each question had 5 possible answers using a verbal rating scale as follows: not at all easy, slightly easy, fairly easy, easy, very easy or not at all good, acceptable, fair, good, very good. Responses were then assigned a numerical value of $1-5$, with 5 corresponding to the most positive response on the rating scale. Results from all 5 individuals were tabulated, resulting in final scores ranging from 5 to 25 . Scores of 20 or higher for a given question were considered good, corresponding to an overall consensus of "easy" or "good" as per user response. All testing was carried out in the BSL-4 training lab at the JC Wilt Infectious Diseases Research Centre in Winnipeg, MB.

\section{$\mathrm{CO}_{2}$ Accumulation}

The level of $\mathrm{CO}_{2}$ in each suit was monitored using a LogiCO2Scout portable Bluetooth sensor (LogiCO2 International AB, Vastra Frolunda, Sweden) over a period of light exercise for 5 minutes (while individuals walked on a treadmill at a pace of 

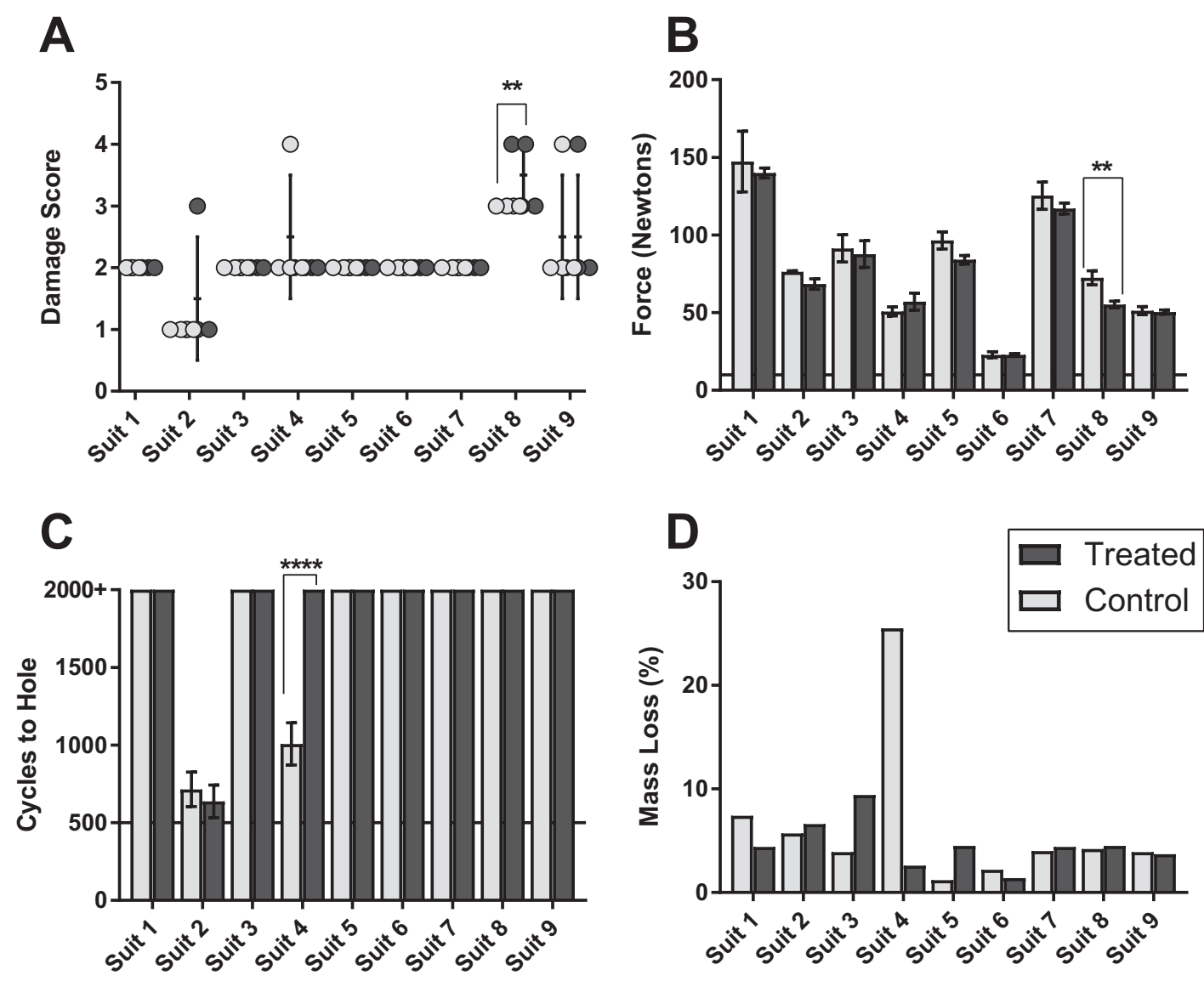

Figure 2. Effect of $5 \%$ Micro-Chem Plus ${ }^{\mathrm{TM}}$ treatment on mechanical properties of suit material swatches. (A) Individual damage scores following up to 40000 cycles of flex cracking (ISO 7854:1995); (B) mean puncture force required to penetrate materials (ISO I3996: I999); and (C) abrasion cycles required for hole formation (EN 530:20I0) were assessed following 5 days of exposure to 5\% Micro-Chem Plus ${ }^{\mathrm{TM}}$ (treated, yellow), or no treatment (control, purple). (D) Mass loss of swatches before and after abrasion testing. Black lines in graphs B and C indicate minimum performance requirements for Type IC protective suits.

1.5 miles per hour, simulating slow and steady movements required when working in the BSL-4 lab. At the 2:30 mark, participants disconnected from supplied air for a total of 45 seconds, reconnecting at the $3: 15$ mark. $\mathrm{CO}_{2}$ readings were recorded at 1:00, 2:00, 2:30, and every 15 seconds thereafter up to 5:00.

\section{Results}

\section{Effect of 5\% Micro-Chem Plus ${ }^{\mathrm{TM}}$ on Mechanical Resistance of Suit Material}

Material testing showed varying degrees resistance across different suit fabrics, however all swatches surpassed requirements for Type $1 \mathrm{C}$ chemical protective suits following exposure to $5 \%$ Micro-Chem Plus ${ }^{\mathrm{TM}}$. Of the various fabrics tested, butyl coatings consistently showed the lowest compatibility with the disinfectant, while a neoprene-coated fabric repeatedly showed enhanced mechanical resistance following treatment. When resistance to flex-cracking was analyzed, only fabric from suit 2 (butyl-coated) had a small hole develop in 1 of 4 treated samples after 15000 cycles (minimum requirements for Type 1C Class 4 protective suits). All other materials were further tested to 40000 cycles of flex-cracking and no differences were observed between control and Micro-Chem Plus ${ }^{\mathrm{TM}}$-treated swatches in 6 of the remaining 8 suits (Figure 2A). Material from suit 8 , a butyl and viton-coated fabric, had a significantly higher damage score after exposure to the disinfectant; while neoprene coated fabric from suit 4 had lower damage scores following Micro-Chem Plus ${ }^{\mathrm{TM}}$ exposure compared to the untreated control.

When testing for resistance to puncture, all materials surpassed requirements for Type $1 \mathrm{C}$ suits (resistance $>10 \mathrm{~N}$ ) and the majority of materials tested showed insignificant differences when control and treated swatches were compared. The largest difference in puncture resistance was observed in Micro-Chem Plus ${ }^{\mathrm{TM}}$-treated material from suit 8 compared to untreated controls, whereas exposure to the disinfectant appeared to enhanced resistance of suit 4 (Figure 2B). Finally, abrasion resistance testing revealed that all suit materials, Micro-Chem Plus ${ }^{\mathrm{TM}}$-treated and untreated, surpassed performance requirement of standard ( $>500$ cycles to hole) for Type 
1C garments. As with other mechanical tests, suit 2 fabric showed decreased performance following treatment with $5 \%$ Micro-Chem Plus ${ }^{\mathrm{TM}}$ compared to the untreated control, while material from suit 4 showed significantly enhanced resistance (Figure 2C). For further comparison, swatches were weighed before and after abrasion testing to determine the effect on overall mass loss. Similar to abrasion testing results, a negligible difference was observed in mass losses when control and treated swatches were compared. Only material from suit 4 showed a noteworthy difference between treatment groups, with results complementing those observed for all mechanical resistance tests. Here, Micro-Chem Plus ${ }^{\mathrm{TM}}$-treated swatches showed only $2.6 \%$ mass loss following 2000 abrasion cycles, whereas untreated controls lost over $25 \%$ of their mass (Figure 2D).

\section{User Preference}

The suitability of 9 different positive pressure suits for use in the BSL-4 laboratory was evaluated through participantdriven exercises involving experienced suit-trained staff. Three of these suits, numbers 5,6 , and 9 , are widely used in BSL-4 facilities around the world, while the others have yet to be utilized in such laboratory settings to the best of our knowledge. All activities were performed in a mock BSL-4 training laboratory to best capture the realities of working in a functioning maximum containment lab environment. Survey responses were converted from verbal rating scales to numerical values, and questions receiving scores of 20 (out of the maximum of 25), corresponding to responses of "good" or "easy" were considered acceptable. Analyses of particular features showed visors with highest degrees of visibility received the best scores, while gloving systems utilizing tape had comparable scores to those with external ring-lock mechanisms.

Of all the suits tested, results showed a clear preference for suit 5 , receiving scores above 20 in 17 of the 21 survey questions (Figure 3). Users assigned particularly high scores to the suit material, which was found to be light, flexible and comfortable for sitting and moving about the lab. This suit also received the highest scores of all models tested relating to internal airflow distribution as well as the visor, which provides nearly 360 -degree visibility due to its completely transparent construction material.

Suit 9 earned the second-highest user ratings with scores of 20 or greater in thirteen of the 21 survey questions. This suit scored particularly high in questions relating to the donning and doffing processes, facilitated by the light construction material similar to that of suit 5 , combined with a long and smooth zipper that opens from the knee up to the top of the visor.

Positive pressure suit models that have never been previously used by BSL-4 laboratories were also tested for their suitability for the maximum containment lab environment. Suits $1-4,7$, and 8 offered some unique safety and ergonomic features, including an internal support belt and a minimum supply airflow warning whistle that activates when supply air pressure is below manufacturer's minimum requirements. Participant comments indicated the belts were generally appreciated, though some found them to be an added complication to the donning process. While the airflow warning whistles largely remained silent, they occasionally activated if users were slow to connect or disconnect from supply air hoses. Most importantly, all of these suits featured visors with approximately 180 -degree visibility, greatly impacting peripheral vision. When the laboratory strobe light was activated to simulate a critical system failure, the majority of participants were unable to see the alarm while working in the biosafety cabinet until a reflection was noticed in the sash.

Suits 1-4, identical in design but differing in suit material, showed great variation in scores obtained though were generally were not popular with study volunteers. In addition to issues with peripheral vision, the dry suit-like locking cuff mechanism for glove attachment requires that sleeves be turned completely inside out to change a glove. This proved extremely challenging for most users, and in the case of suit 1 its extremely heavy and rigid material prevented most participants from performing the task. All of these suits also contain an internal collar providing support for air supply hoses in the hood area. This structural aspect also proved extremely uncomfortable for users and interfered with the use of headsets inside the suit. Of these 4 models, only suit 2 obtained an acceptable rating on any of the survey questions, scoring $20 / 25$ in only 2 of the 21 questions, both related to suit material.

Suits 7 and 8 were similarly included as novel models with potential utility for the BSL-4 laboratory. Compared to the first 4 suits, suits 7 and 8 received better overall scores for the donning and doffing processes as well as glove changing procedure, which does not require sleeves to be inverted. However, the hard locking ring mechanism for glove attachment regularly caught on the front grille cabinet while participants worked in the biosafety cabinet. Other aspects of these suits receiving common complaints were the drooping visors during BSC work and the Velcro splash guard covering the zipper, which complicated the donning and doffing procedures.

Finally, suit 6 received intermediate reviews, scoring 20 or higher on 4 of the survey questions. The material used for the body of this suit is the only one that does not contain a coated fabric, but rather is a pliable plastic material. The short, angled zipper design combined with the slimmer fit of this suit resulted in lower scores related to the donning process for the head area in particular, with most participants struggling to don the head area when wearing headsets. Like suits 5 and 9, this suit relies on external taping for glove fixation.

\section{$\mathrm{CO}_{2}$ Accumulation}

To measure the levels of $\mathrm{CO}_{2}$ inside the suit, participants were asked to walk on a treadmill at a slow pace $(1.5 \mathrm{mph})$ for a total of 5 minutes. To simulate a hypothetical emergency situation, following 2.5 minutes of walking each person disconnected from the umbilical air supply for a period of 45 seconds, 


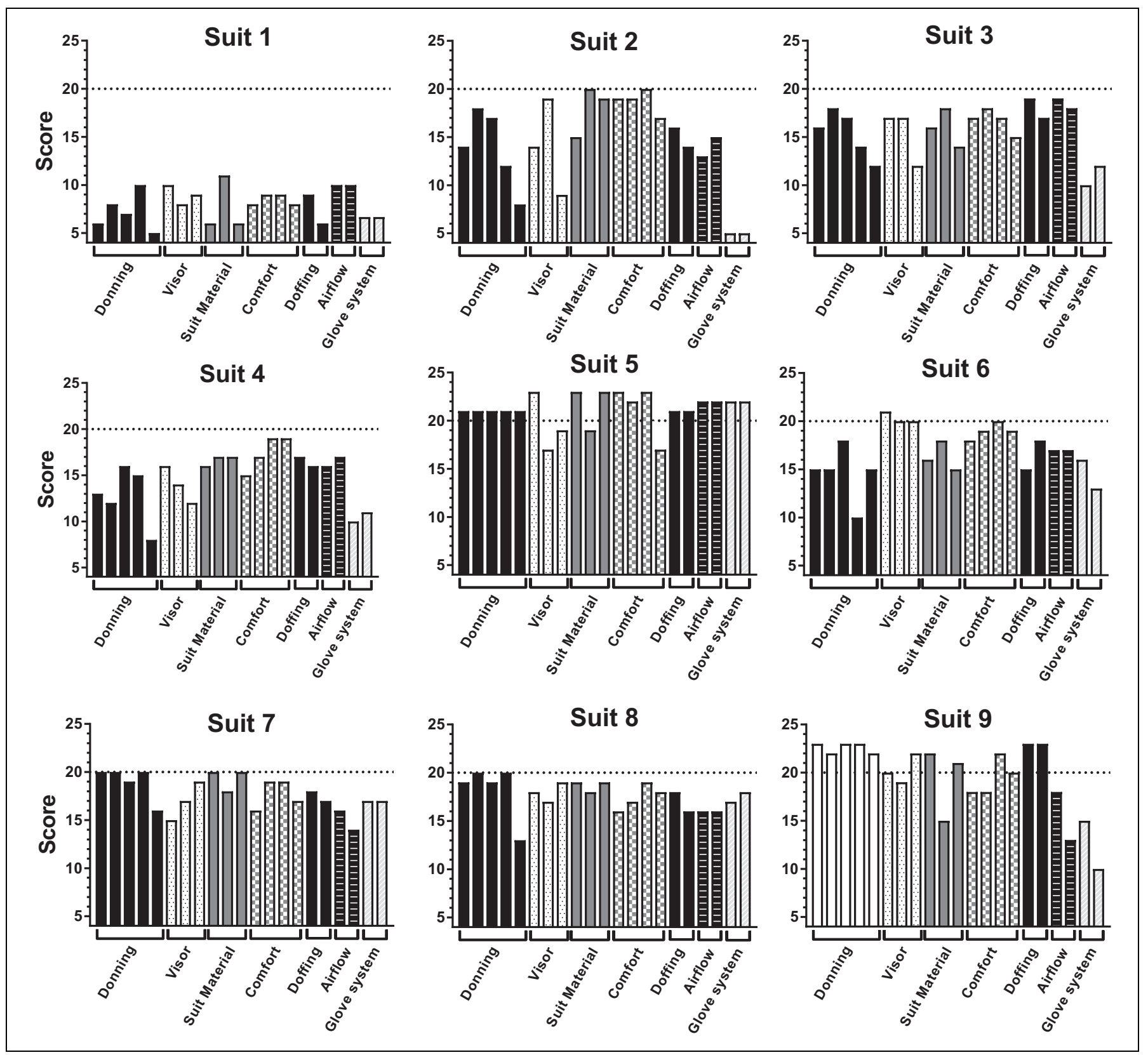

Figure 3. Summary of user preferences for 9 different positive pressure suits for use in the BSL-4 laboratory based on survey responses. Answers to 21 questions grouped categorically were assigned numerical scores from 5 to 25 , with mean scores determined based on 5 respondents per suit. Scores of 20 or higher (dotted line) indicate good performance.

continued walking and reconnected for the remainder of the 5minute exercise. When supply air was connected, all suits provided a safe working environment with $\mathrm{CO}_{2}$ levels well below the National Institute for Occupational Safety and Health (NIOSH) 8 hour time-weighted average occupational exposure limit of $1 \%$ (NIOSH). During and following air disconnect, differences between models were observed. All suits showed a similar trend of rising $\mathrm{CO}_{2}$ levels within the visor area between 15 and 30 seconds post-disconnect (Figure 4, shaded areas), with levels continuing to rise up to 30 seconds after reconnecting to supply air. Overall, during and immediately following a period of 45 seconds without supply air, all of the suits tested maintained $\mathrm{CO}_{2}$ concentrations below $1.6 \%$. The microenvironment in suit 5 exposed participants to lowest $\mathrm{CO}_{2}$ levels overall, reaching maximum concentrations of only $0.82 \%$. Conversely, suit 6 exposed users to the highest levels of $\mathrm{CO}_{2}$ both while connected to supply air and during periods of disconnect in comparison with other models. Interestingly, some models resulted in great variations in $\mathrm{CO}_{2}$ levels when individual participants were compared, particularly with suits 1 and 2, whereas others (suits 4 and 8) had little differences between individual participants. 


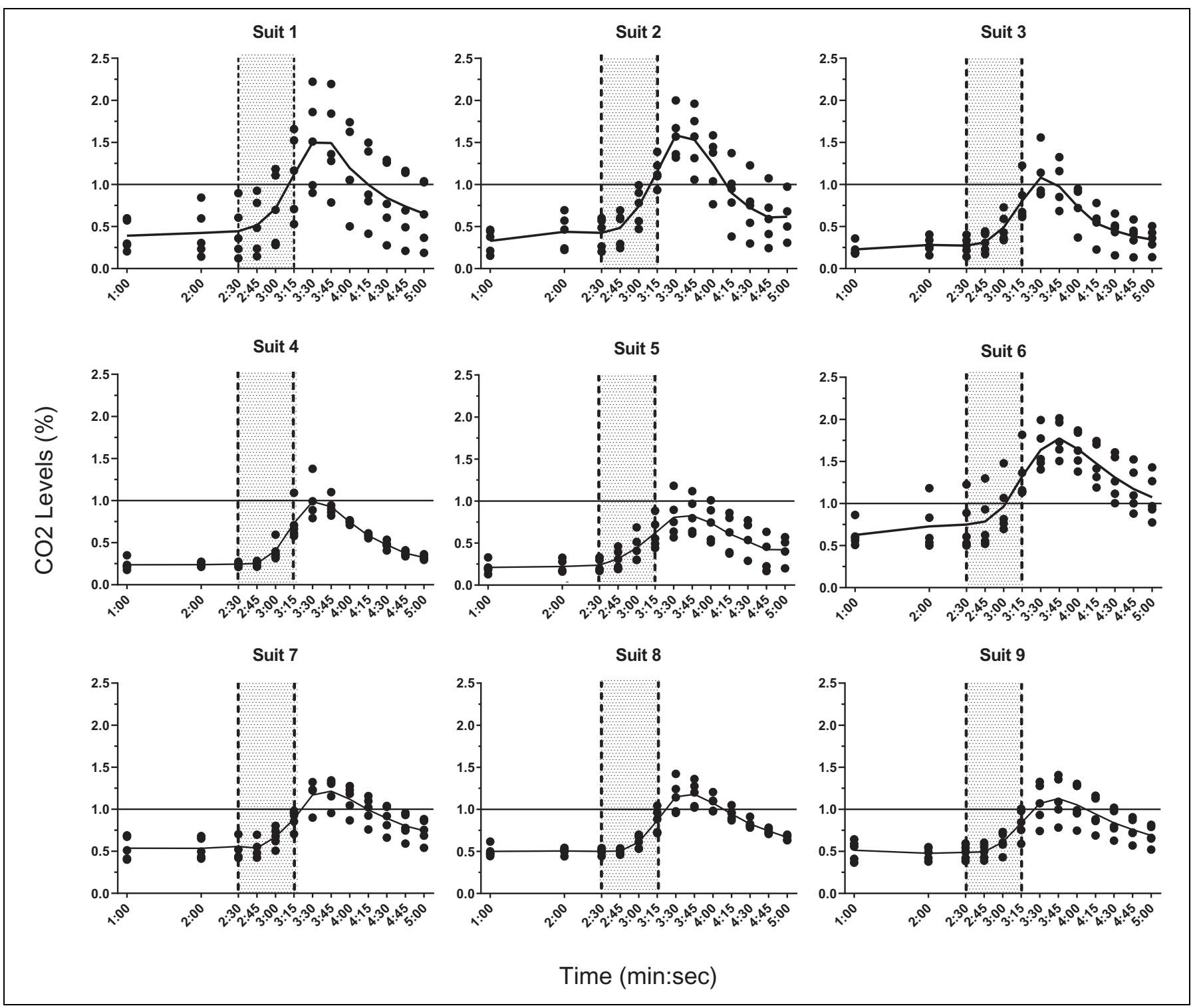

Figure 4. $\mathrm{CO}_{2}$ accumulation in positive pressure suits during a period of light exercise $(\mathrm{n}=5$ per suit). Shaded areas from 2:30 to 3:15 indicate period of disconnect from supply air. Black horizontal lines indicate $\mathrm{NIOSH}$ established 8-hour time-weighted average exposure limits to $\mathrm{CO}_{2}$.

\section{Discussion}

National and international regulations presiding over BSL-4 suit laboratories require the use of positive pressure, selfencapsulating suits that deliver HEPA-filtered air to the user. With no prescriptive requirements for specific construction material or air flow levels, individual facilities have a significant degree of freedom in choosing the make and model(s) of suits for their staff. However, despite the number of potentially acceptable suits already used in other industries and the desire to explore alternative options, ${ }^{8}$ the global BSL-4 community largely relies on a limited number of models due to their longstanding use in other facilities. To address this point, the present study provided objective and subjective evaluations of a broad range of positive pressure suits by experienced BSL-4 laboratory staff to assess their suitability for use in the BSL-4 lab and large animal cubicle. Ultimately, results obtained suggest that 2 of the suit models widely used by the BSL- 4 community were most user-friendly and offered excellent compatibility with the chemical disinfectant (Micro-Chem Plus $^{\mathrm{TM}}$ ) used at our facility.

As every facility differs in its engineering and operational aspects, inclusion of site-specific requirements and activities in any assessment provides the most useful information for a given laboratory. A requirement of all BSL-4 suit laboratories is a chemical decontamination shower upon exit from the laboratory. ${ }^{2,3,9}$ As such, suits must withstand repeated exposure to the chemical disinfectant used at a particular facility. Analyses of mechanical resistance of suit materials following exposure to $5 \%$ Micro-Chem Plus ${ }^{\mathrm{TM}}$, the disinfectant used for many BSL-4 chemical showers in Canada and the United States, ${ }^{10,11}$ 
proved that the majority of materials showed no decreased performance in resistance tests for puncture, abrasion and flex-cracking compared to untreated control swatches. Only butyl-coated fabrics appeared to suffer deleterious effects following 5\% Micro-Chem Plus ${ }^{\mathrm{TM}}$ treatment, as evidenced by performance of materials from suits 2 and 8 . The general weakness of material from suit 2 was clearly demonstrated by its poor performance in abrasion testing, while treated swatches from suit 8 were the only ones to show significant decrease in force required for puncture compared to untreated controls. Assessment of resistance to flexcracking revealed decreased performance in Micro-Chem Plus $^{\mathrm{TM}}$-treated swatches from both suits 2 and 8 compared to untreated controls.

Interestingly, a previous publication assessing material from suit 5 revealed that exposure to $2.5 \%$ per-acetic acid for 7 days had detrimental effects on mechanical resistance. ${ }^{5}$ Whether increasing exposure time to $5 \%$ Micro-Chem Plus ${ }^{\mathrm{TM}}$ would have resulted in similar observations cannot be inferred, however the 5-day test period used in the present experiments, corresponding to 2 chemical showers daily for 5 years, likely represents the maximum number of chemical showers a suit would experience over its shelf life based on manufacturer's indications or institutional change out policy. These results highlight the importance of suit selection based on facilityspecific factors and clearly demonstrate that the choice disinfectant used for the chemical shower may have profoundly different effects on suit materials.

In addition to objective analyses of suit material strength and disinfectant compatibility, the opinions of experienced laboratorians was an important factor in determining whether suits were potentially acceptable for BSL-4 lab use. Results from survey questions indicated a number of general features that either contributed to or detracted from overall comfort and user-friendliness of the suits. In general, those with lighter and less rigid materials were preferred by study volunteers, though additional structural aspects such as visor construction and ease of donning outweighed construction material alone. Visors with $<300^{\circ}$ visibility were deemed unacceptable, not only from user feedback but also as poor peripheral vision interfered with participants' ability to recognize visual alarms. In addition, suits with locking cuff glove mechanisms were extremely disliked by study volunteers and proved too difficult for most participants to change gloves on their own.

Prior to this study the only published information on $\mathrm{CO}_{2}$ accumulation in positive pressure suits came from a single supplier, measuring buildup of $\mathrm{CO}_{2}$ over a period of 5 minutes when the test subject was disconnected from supply air. ${ }^{12}$ In the present work, $\mathrm{CO}_{2}$ levels measured during a period of light exercise while users were connected to supply air provided insight into the microenvironment that laboratorians are exposed to while working in the BSL-4 lab under light stress. Despite different supply airflow rates, all suits provided a microenvironment where users were exposed to less than the time weighted average (TWA) limits of $1 \% \mathrm{CO} 2$ as established by NIOSH. ${ }^{13}$ While the suit with highest airflow provided best results, general trends correlate a combination of overall suit construction and supply air flow rates with lower levels of $\mathrm{CO}_{2}$ accumulation.

As a general rule and in accordance with positive pressure suit function, BSL-4 staff members are required to stay continuously connected to supply air, disconnecting only for brief periods when moving about the laboratory. However, to further complement information gathered on exposure levels during normal activity, $\mathrm{CO}_{2}$ levels were also measured during and immediately after a 45 second period of disconnect from supply air. During this period with no supply air connection, results similarly showed that none of the suits exposed users to even the NIOSH short term exposure limits (TWA of $3 \%$ $\mathrm{CO} 2$ over 10 minutes). While this is not an expected situation under normal operating conditions, these results are highly valuable for training on emergency procedures and may help staff members to avoid panic if air supply becomes unexpectedly interrupted for a brief period of time.

With the global expansion of BSL-4 facilities, including many in the commissioning and construction phases, the availability of data to assist in selecting the most appropriate suit model based on end-user needs is of high value to the international BSL-4 community. Results from the present study indicate that suit selection must involve a holistic approach rather than a focus on one particular feature. From a user preference perspective, lighter material combined with balanced air distribution and high visibility resulted in the most favorable working conditions. By combining this information with facility-specific factors, including delivery air capacity and material compatibility with the disinfectant used for the chemical decontamination shower, laboratories may be better equipped to consider new models to fit their needs. Finally, responses from the user survey may provide useful information for manufacturers interested in providing positive pressure suits specifically tailored to the BSL-4 community.

\section{Acknowledgments}

We graciously acknowledge the help of our suit study volunteers, Greg Smith, Brad Pickering, Brad Collignon, Graham Casey, Nikesh Tailor, Mathieu Pinette, Glenn Clark, Cory Nakamura, Chandrika Senthilkumaran, Matthew Suderman, Andrea Kroeker, Shawn Babiuk, and Yohannes Berhane, for dedicating their time to participate in our study. We further thank the Les Wittmeier for his assistance with experimental setup and Edwin Ledesma and Don Whitworth at the JC Wilt Infectious Disease Research Centre for their technical assistance during the suit study. We are also grateful to Jay Krishnan for his input into the study design and manuscript review. Finally, we thank the Canadian Safety and Security Program for funding this research through the Biosafety Level 4 Zoonotic Disease Laboratory Network (BSL4ZNET).

\section{Declaration of Conflicting Interests}

The author(s) declared no potential conflicts of interest with respect to the research, authorship, and/or publication of this article. 


\section{Statement of Ethical Approval}

The Ethics Committee of the University of Manitoba waived the need for IRB approval for this study.

\section{Statement of Human and Animal Rights}

Individual enrollment was on a fully voluntary basis and participants were free to leave the study or forego any particular activity at any point in time.

\section{Statement of Informed Consent}

Written informed consent for inclusion, collection, and use of $\mathrm{CO} 2$ data generated and survey responses for the present study was obtained through email communications following a letter of invitation to participate in the study, and was confirmed verbally in the presence of two witnesses on the day(s) of active participation.

\section{Funding}

The author(s) disclosed receipt of the following financial support for the research, authorship, and/or publication of this article: Financial support was provided by the Canadian Safety and Security Program through the Biosafety Level 4 Zoonotic Disease Laboratory Network (BSL4ZNET).

\section{Prior Presentation}

Kasloff SB, Marszal P, Weingartl HM. Evaluation of 9 positive pressure suits for use in the Biosafety Level-4 Laboratory. Poster presented at: ABSA International 60th Applied Biosafety Meeting; October 13-18, 2017; Albuquerque, NM.

\section{References}

1. ILC Dover. Chemturion ${ }^{\mathrm{TM}}$ Bio Safety Level A suit of armor for hazardous environments; 2018. Available at: https://www.ilcd over.com/wp-content/uploads/2018/03/MKT-0065_Chemturion1.pdf. Accessed June 20, 2018.

2. Chosewood LC, Wilson DE, eds. Biosafety in Microbiological and Biomedical Laboratories. 5th ed. Washington, DC: US
Department of Health and Human Services, Public Health Service, Centers for Disease Control and Prevention, National Institutes of Health; 2009.

3. World Health Organization. Laboratory Biosafety Manual. 3rd ed. Geneva, Switzerland: World Health Organization; 2004.

4. Government of Canada. Canadian Biosafety Handbook (CBH). 2nd ed. Ottawa: Government of Canada; 2016.

5. Kümin D, Krebs C, Wick P. How to choose a suit for a BSL-4 Laboratory-the approach taken at SPIEZ LABORATORY. Applied Biosafety. 2011;16(2):94-102.

6. Steward JA, Lever MS. Evaluation of the operator protection factors offered by positive pressure air suits against airborne microbiological challenge. Viruses. 2012;4(8):1202-1211.

7. Standards Council of Canada. CAN / CGSB / CSA-Z16602: 14Protective Clothing for Protection Against Chemicals-Classification, Labeling and Performance Requirements. Ottawa, ON: Standards Council of Canada; 2014.

8. Harbourt D. BSL-4 User Survey Results Aiding in the Design of the Next Generation of Positive pressure Suits. Unpublished presentation.

9. Government of Canada. Canadian Biosafety Standard (CBS). 2nd ed. Ottawa, ON: Government of Canada; 2015.

10. Klaponski N, Cutts T, Gordon D, Theriault S. A study of the effectiveness of the containment level-4 (CL-4) chemical shower in decontaminating dover positive pressure suits. Applied Biosafety. 2011;16(2):112-117.

11. Parks S, Gregory S, Fletcher N, et al. Showering BSL-4 suits to remove biological contamination. Applied Biosafety. 2013;18(4): 162-171.

12. ILC Dover Model 35 Chemturion $\mathrm{CO}_{2}$ Test; 1999. Available at: http://www.ilcdover.com/sites/default/files/C02_Buildup.pdf. Accessed January 5, 2017.

13. National Institute for Occupational Safety and Health (NIOSH). Carbon dioxide; 2011. Available at: https://www.cdc.gov/niosh/ pel88/124-38.html. Accessed April 3, 2018. 